\title{
Body Size Influences Mating Success of the Eucalyptus Longhorned Borer (Coleoptera: Cerambycidae)
}

\author{
Lawrence M. Hanks, ${ }^{1,2}$ Jocelyn G. Millar, ${ }^{1}$ and Timothy D. Paine ${ }^{1}$
}

Accepted September 12, 1995; revised January 5, 1996

Both sexes of adult Phoracantha semipunctata $F$. (Coleoptera: Cerambycidae) congregate on stressed Eucalyptus that are the larval hosts. In a field study, 721 adult $\mathrm{P}$. semipunctata captured on host trees varied considerably in body size with the largest individuals being about twice the length of the smallest. Females that were paired with a mate were similar in size to solitary females, suggesting that the probability of a female being mated was not affected by her size. However, large males had greater success than smaller males in obtaining mates. Male P. semipunctata rely on antennal contact to locate and identify females on the larval host. Therefore, the rate at which males search for mates is a function of the area swept by their antennae per unit time. Because of their greater antennal spread, large males were able to search for females at double the rate of the smallest males. Large males also dominated in aggressive contests for females. The superior abilities of large male $\mathrm{P}$. semipunctata in both locating and defending mates account for the influence of body size on mating success.

KEY WORDS: insect; mating; body size; male competition; associative mating; Cerambycidae.

\section{INTRODUCTION}

Body size often directly influences the reproductive success of animals (e.g., Alcock, 1993). Among insects, large females commonly are mated more often due to size-related mating preferences of males, while large males usually edge out smaller rivals in aggressive contests over females (reviewed by Thornhill and Alcock, 1983). However, mating success of males depends not only on their fighting skills, but also on their ability to locate prospective mates (Otte, 1979).

\footnotetext{
'Department of Entomology, University of Califomia, Riverside, California 92521.

${ }^{2}$ To whom correspondence should be addressed.
} 
Variation in mating success within insect populations may be most pronounced when individuals vary greatly in size. For example, substantial variation in body size among long-homed beetles (Coleoptera: Cerambycidae) (Andersen and Nilssen, 1983; Haack and Slansky, 1987) accounts for nonrandom patterns of mating within populations of some species (e.g., Dusham, 1921; Beeson and Bhatia, 1939; Chemsak, 1963; Hughes and Hughes, 1987; Goldsmith, 1987, 1989; Edwards and Linit, 1991). In this study, we investigate the mechanisms by which body size influences mating success of the eucalyptus longhorned borer, Phoracantha semipunctata F. (Coleoptera: Cerambycidae). We present evidence that large males are more successful in mating than smaller males and test the hypothesis that large body size confers an advantage not only in aggressive contests among males, but also in the location of females.

\section{NATURAL HISTORY AND BEHAVIOR OF P. semipunctata}

Phoracantha semipunctata, a native of Australia, was first detected in southern California in 1984, where it continues to be a serious pest of Eucalyptus (Scriven et al., 1986; Paine et al., 1995). Freshly fallen Eucalyptus logs or stressed trees are hosts for the larvae, which penetrate the bark and feed on the cambium (for biology see Hanks et al., 1993). The adults are active in the evening hours and are strong fliers (for adult behavior see Hanks et al., 1996). They eat the nectar and pollen of Eucalyptus, and both sexes are attracted to the larval hosts. There, females slowly wander over the bark surface, probing with their ovipositors for loose bark under which they deposit their eggs. In contrast, males run almost constantly with antennae wide spread, locating their mates primarily by antennal contact. Neither sex appears to discriminate among potential mates and nearly every encounter between the sexes results in a characteristically brief copulation [averaging $28.0 \pm 2.1 \mathrm{~s}$ (Hanks et al., 1996)]. Following copulation, the male accompanies his mate, grasping her elytra with his forelegs as she searches for oviposition sites, and copulation may be repeated at intervals. Males and females may remain paired for the entire period that beetles are present on the larval host. Rival males may attempt to displace paired males by lashing with the antennae, head butting, and biting, but these conflicts rarely result in injury.

\section{MATERIALS AND METHODS}

\section{Assortative Mating and Influence of Size on Mating Success}

We investigated how body size influences mating success of $P$. semipunctata by capturing beetles that were congregating on three large Eucalyptus viminalis de La Billardière ( $\approx 3 \mathrm{~m}$ in basal circumference) that stood within $12 \mathrm{~m}$ of 
one another on the campus of the University of California, Riverside. These trees experienced a period of water deficit during summer 1990 and had became highly attractive to the beetles. Within a few weeks, all three trees were dead and were heavily infested by borer larvae. Beetles were collected on 22 nights between 22 July and 28 August 1990 beginning at dusk, when they were most abundant, for a minimum of $1 \mathrm{~h}$. Density of beetles was highest just after sunset and dropped off sharply after $2 \mathrm{~h}$. Beetles were collected from the lower $2.5 \mathrm{~m}$ of the tree trunks.

From the three study trees, we captured 721 beetles (191 $\$: 530$ o $^{*}$ ), including 80 pairs (male accompanying a female). Paired beetles were undoubtedly mated since mating invariably occurs at first contact (Hanks et al., 1996). We assumed that males paired with females when captured had higher mating success (for the night of capture) than solitary males (Hanks et al., 1996).

Nonrandom patterns of mating based on body size may arise within populations due to size-related preference or physical constraints which hinder mating between beetles of different sizes (Burley, 1983; Ridley, 1983). Under these conditions, body sizes of paired females and males may be correlated. We tested for such size-assortative mating by regressing male size on female size for the captured mated pairs. Linear relationships between male and female body size were tested with the coefficient of determination [ $r^{2}$ (Sokal and Rohlf, 1981)], a significant positive linear relationship would indicate size-assortative mating.

We examined the influence of body size on mating success for both sexes by comparing the sizes of beetles that were paired with a mate when captured with those that were solitary. Distributions of body lengths for paired and solitary individuals were compared using a Wilcoxon rank-sum test (Sokal and Rohlf, 1981; SAS Institute, 1988).

\section{Influence of Male Body Size on Mate Location Ability}

Because male $P$. semipunctata locate females on the larval host by antennal contact (Hanks et al., 1996), the probability of locating a mate is a function of the rate at which the male sweeps the bark surface with his antennae. This area sweep rate is a function of the width of the antennal spread and the walking speed, both of which may be strongly influenced by body size. Antennal spread is determined by the length of the antennae. We examined the relationship between antenna length (base of scape to tip of flagellum) and body size by measuring 30 individuals of each sex that represented a wide range of sizes (beetles reared from field-infested logs in fall 1992). To test for differences between sexes in slopes of regression lines, we conducted an analysis of covariance; a significant interaction between the class variable (sex) and the covariate (body length) would indicate that slopes were significantly different [GLM Procedure (SAS Institute, 1988)]. 
To examine the relationship between body size and walking speed, we videotaped male $P$. semipunctata both in the laboratory and in the field (see Videotaping Procedures below). In the laboratory, we measured walking speeds by videotaping beetles walking on a flat $1-\mathrm{m}$ square of brown butcher paper with overhead lighting (incandescent bulbs) at $28^{\circ} \mathrm{C}$. Each beetle was videotaped three times and measurements of walking speed were averaged. Regression was used to test for linear relationships between body size and walking speed (Sokal and Rohlf, 1981). The 56 study beetles were reared from logs that had been naturally infested in the field and averaged $2.13 \pm 0.42 \mathrm{~cm}$ (mean \pm SD) in body length. For less than 7 days prior to setting up the experiment on 13 July 1992 beetles were kept in mixed-sex cages on a diet of sugar water [rearing procedures described by Hanks et al. (1993)].

To examine how body size influenced area sweep rate, we measured antennal spread of the same videotaped males by freezing the frame at arbitrary points during each run, then measuring with a ruler the distance between the distal ends of the antennae (a correction factor allowed calculation of the true antennal spread; see Videotaping Procedures). A mean was taken of the antennal spread measurements for each beetle, and the area swept by the antennae per unit time was calculated by multiplying mean antennal spread by mean walking speed. We used regression analysis to test for linear relationships between body size and area sweep rate (Sokal and Rohlf, 1981).

In the field, we studied the influence of male body size on mate location abilities by videotaping beetles that were visiting fresh Eucalyptus tereticornis Small logs (10 logs, $15-30 \mathrm{~cm}$ in diameter and $\approx 2 \mathrm{~mm}$ in length) that were stacked in a grove of Eucalyptus. The log pile was dimly illuminated with a red light and the videocamera was mounted on a tripod about $2 \mathrm{~m}$ from the $\log$ pile. Sixty-seven beetles were videotaped on 16 evenings ( 2000 to 2300 ) between 30 July and 17 August 1992, and walking speed and area sweep rate were calculated as discussed for the laboratory study. These beetles averaged $2.41 \pm 0.42 \mathrm{~cm}$ in body length.

The relationship between body size and mate searching rate in the field could be obscured by temperature effects. We investigated how walking speed is influenced by ambient air temperature by videotaping walking beetles in the laboratory at four room temperatures: $17,21,25$, and $28^{\circ} \mathrm{C}$. The same 17 males (representing the full range of body sizes and $<12$ days in age) were used to measure walking speed at each temperature on 26 August 1992. After each temperature change, males were allowed to equilibrate for $3 \mathrm{~h}$ in individual petri dishes. To determine if temperature had an effect, we tested for differences between slopes of regression lines for walking speed against body size at different temperatures using analysis of covariance [GLM Procedure (SAS Institute, 1988)]. In this analysis, if the interaction between the temperature variable and the covariate (body length) is not significant (slopes not significantly dif- 
ferent), the probability value for the temperature variable could be used to determine if the heights of the regression lines were different, testing the hypothesis that walking speed varied with temperature.

To determine if air temperature affected beetle performance in the field, temperature measurements at the time of videotaping were obtained from a California Irrigation Management Information System weather station located $<0.5 \mathrm{~km}$ away. We tested the temperature effect by including it as a term in the regression model for area sweep rate against body size.

\section{Influence of Male Body Size on Fighting Ability}

Large-male mating advantage in insects is commonly a result of superior abilities in male-male contests for females (Thomhill and Alcock, 1983). We studied how body size affected the fighting ability of male $P$. semipunctata by caging two males with a single female and observing male interactions. Cages were cylinders of aluminum window screen $(12 \mathrm{~cm} \times 12 \mathrm{~cm}$ in diameter) with 14-cm-diameter plastic petri dishes on the top and bottom. Beetles became active soon after overhead lights were turned off, and observations of behavior under dim red light conditions were recorded continuously on an audio recorder.

Combatant males were scored as "winners" or "losers" depending on how the outcome of a contest affected mating opportunity: (1) a challenging male (attacking a male that was paired with a female) was scored the winner if he succeeded in splitting the pair, rendering the female available for mating; and (2) defending males (paired with the female) were considered the winner if they fended off the challenger and remained paired with the female. This method of scoring male contests in beetles is similar to that of McCauley (1982). Because the outcome of aggressive contests between males of different body sizes was not dependent on which male was originally paired with the female (body size effects were consistent whether a male challenged or defended), we combined the scores for the two types of contests.

Confining beetles to these small cages placed them under conditions of unnaturally severe conflict. To compensate for this, we recorded the outcomes of only the first five interactions between males. Within a cage, the male winning the greater proportion of five interactions was considered the "overall winner." We tested for an influence of male body size on fighting ability by plotting body lengths of losing males against those of winning males. Differences between body lengths of losers and winners were tested by paired-comparison $t$ tests (Sokal and Rohlf, 1981; SAS Institute, 1988).

We used 45 pairs of males in the fighting arenas, and contestants were chosen to represent a broad range of size differences. Beetles were reared from field-infested logs, were kept in the laboratory on a diet of sugar water prior to the experiment, and were $<1$ week old. Males within a cage were of the same 
age and each beetle was used only once. The study was conducted in the afternoons and evenings on 14 days between 20 June and 28 July 1991 .

In the field, we investigated the influence of male body size on fighting ability by videotaping adult $P$. semipunctata on the same pile of Eucalyptus logs used in the mate location study above. Because fighting among males often resulted in one or both males disappearing from view, we could observe only one contest per pair of males. Thirty-four pairs of combatant males were scored winners or losers by the same criteria used in the laboratory study (above) and differences between body lengths of losers and winners were tested by paired comparison $t$ tests (Sokal and Rohlf, 1981; SAS Institute, 1988).

\section{Videotaping Procedures}

To videotape beetles under dim red light conditions, we used a low-light surveillance camera (Panasonic, Tokyo, Japan, Model WV-1350A) with a slowmotion video recorder (Sony, Tokyo, Japan, Model SLO-420) and a high-resolution monitor (Shiba Electric Co. Ltd., Tokyo, Japan, Model VU-903U). Walking speed of videotaped beetles was estimated by measuring distance traveled across the video screen, and timing this movement with a stopwatch at $1 / 5$ playback speed for greater accuracy. Walking substrates (butcher paper, field logs) were marked with a scale of $5-\mathrm{cm}$ increments, and the size of these increments on the video screen provided a correction factor for length $(=5 \mathrm{~cm} /$ length of increment on the video screen). By multiplying measurements taken from the video screen by this correction factor, we could calculate true body size of beetles and distances traveled.

\section{RESULTS}

\section{Assortative Mating and Influence of Size on Mating Success}

Body lengths of 80 paired male and female $P$. semipunctata were only weakly correlated (Fig. 1). Statistical significance was due to a slight tendency for the largest females to pair with large males and the smallest females with medium-sized males. Females that were paired with a mate when captured averaged $2.37 \pm 0.030 \mathrm{~cm}$ in length, only slightly larger than solitary females, which averaged $2.30 \pm 0.028 \mathrm{~cm}$. The distribution of body sizes for paired and solitary females did not differ significantly (Fig. 2, top; Wilcoxon statistic $=$ $1.72, P>0.05$ ), suggesting that the probability of a female being mated was not affected by her size. A mating advantage for larger males was suggested by the skewed distribution of body sizes for paired males compared to solitary males (Fig. 2, bottom; Wilcoxon statistic $=4.36 ; P<0.001$ ). Paired males averaged $2.42 \pm 0.04 \mathrm{~cm}$ in length, $\approx 8 \%$ larger than solitary males, which averaged $2.22 \pm 0.016 \mathrm{~cm}$. 


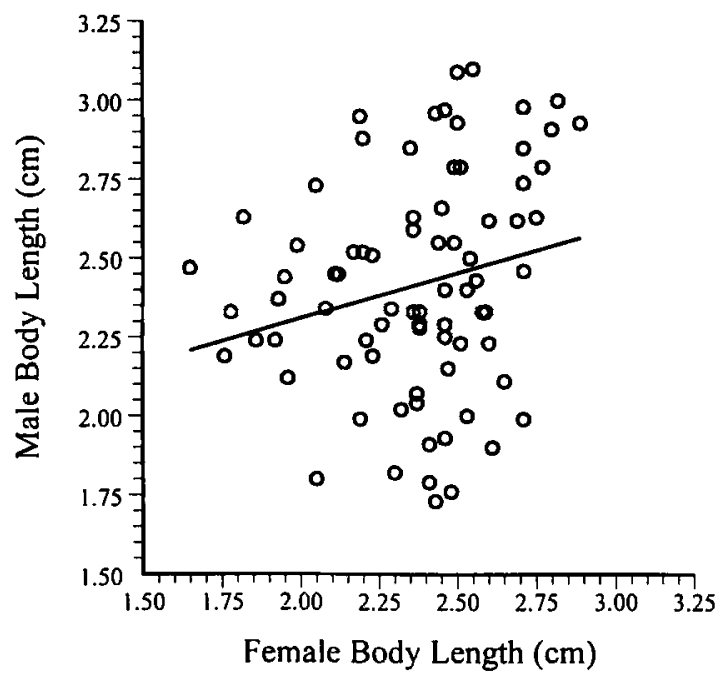

Fig. 1. Relationship between body lengths of mated female and male $P$. semipunctata for 80 pairs captured on host trees on the U.C. Riverside Campus. The best-fit regression equation was $Y=0.288 X+1.73\left(r^{2}=0.038, P=0.046\right)$.

\section{Influence of Male Body Size on Mate Location Ability}

Linear relationships between body length and antennal length differed between the sexes (Fig. 3); the slope for males (1.94) was $76 \%$ greater than that for females (1.1; slopes significantly different, ANCOVA $F_{1.56}=112.9$, $P<0.0001$ ). Thus the discrepancy in antennal length between males and females increased with body size.

In the laboratory studies, walking speeds of male $P$. semipunctata averaged $19.0 \pm 3.1 \mathrm{~cm} / \mathrm{s}$ (mean $\pm \mathrm{SE}$ ) and increased significantly with body size (Fig. 4 , top). However, there was only a $32 \%$ difference in walking speed between the smallest and the largest individuals (calculated from the regression line). Area sweep rate averaged $95.0 \pm 32.1 \mathrm{~cm}^{2} / \mathrm{s}$ and increased with body size more dramatically than walking speed alone (Fig. 4, bottom); the largest males swept with their antennae 2.8 times the area covered by the smallest males. The greater area sweep rate of larger males suggests a potential advantage in locating females on the larval hosts.

Walking speeds of male $P$. semipunctata in the field were only about half those observed in the laboratory study, averaging $9.03 \pm 2.5 \mathrm{~cm} / \mathrm{s}$, and did not appear to vary with body size (Fig. 5, top). Area swept by the antennae per unit time averaged $60.6 \pm 22.3 \mathrm{~cm}^{2} / \mathrm{s}, \approx 35 \%$ slower than that recorded in the laboratory study. Nevertheless, area sweep rate did increase significantly with 
ED Solitary Paired

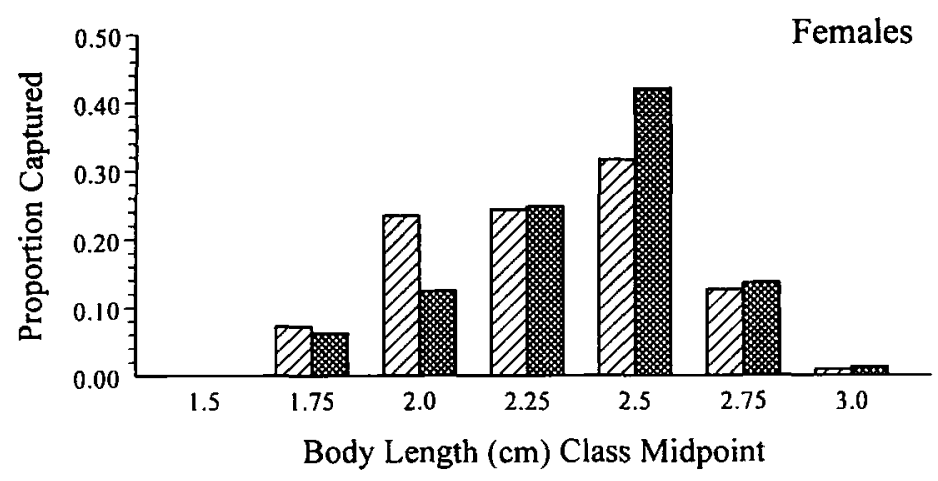

EZJ Solitary Paired

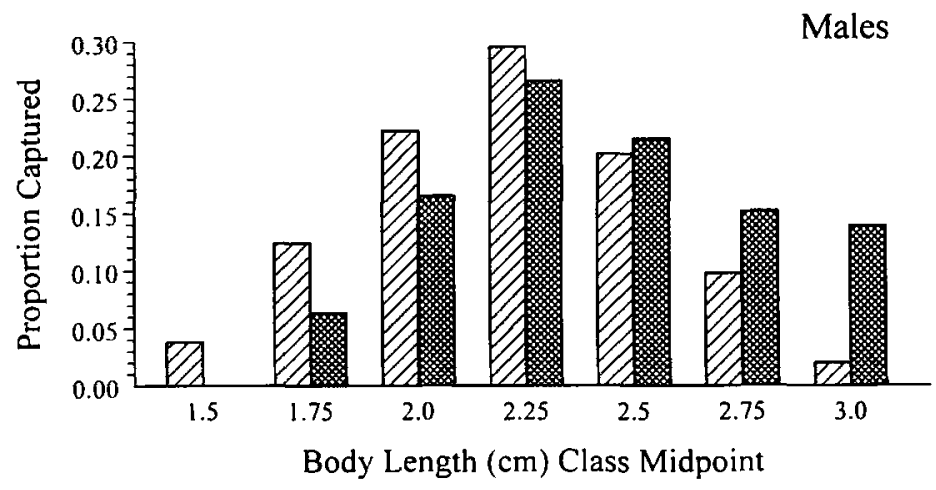

Fig. 2. Frequency distributions of body lengths for female (top) and male (bottom) $P$. semipunctata captured as solitary individuals (111 females, 450 males) versus paired with a mate ( 80 of each sex) from host trees on the U.C. Riverside Campus.

body size and was 2.3 times higher for the largest males compared to the smallest males (Fig. 5, bottom). This finding confirms that the searching efficiency of males in the field increased with body size and that larger males had a competitive advantage in locating mates.

In the laboratory, walking speed was $\approx 60 \%$ faster at warm ambient air temperatures $\left(28^{\circ} \mathrm{C}\right)$ than at cool temperatures $\left(17^{\circ} \mathrm{C}\right.$ ) (walking speeds at 17 , 


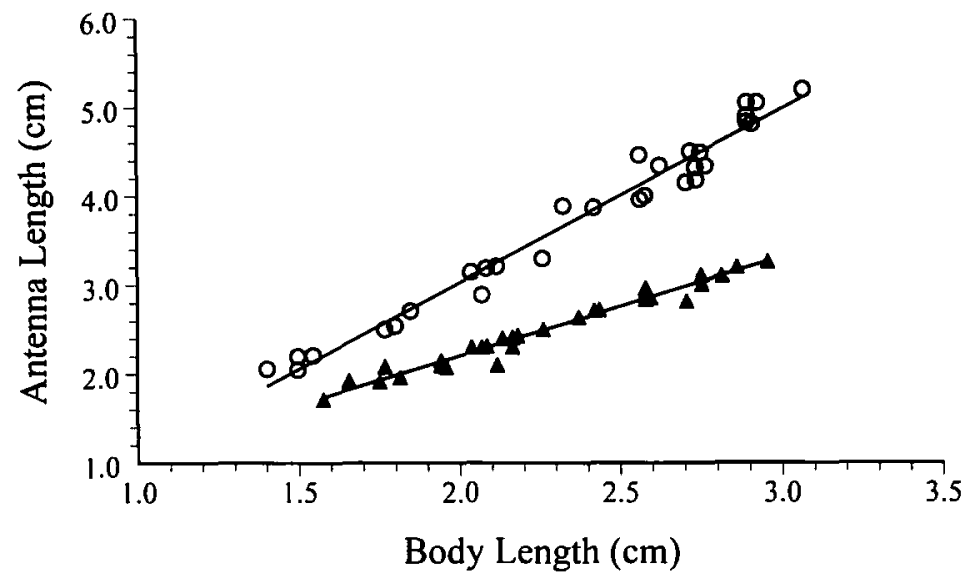

Fig. 3. Relationship between body length and antenna length for $30 P$. semipunctata males (open circles) and females (black triangles). Best-fit regression equations: males, $Y=1.94 X-0.86\left(r^{2}=0.97, P<0.0001\right)$; females, $Y=1.10 X-$ $0.0015\left(r^{2}=0.97, P<0.0001\right)$.

21,25 , and $28^{\circ} \mathrm{C}$ were $12.1 \pm 0.42,13.7 \pm 0.48,17.2 \pm 0.77$, and $19.5 \pm$ $0.65 \mathrm{~cm} / \mathrm{s}$, respectively; means significantly different, $F_{3.62}=5.23, P<$ $0.0001)$. The size-covariate term of the analysis of covariance was not significant $\left(F_{3,59}=1.48, P>0.05\right)$, indicating that slopes of regression lines for walking speed on body length were similar for different temperatures and that the effect of air temperature on walking speed did not vary with body size. These laboratory data suggest that walking speeds of beetles in the field may be strongly influenced by air temperature, contributing to variation in field data used to test the relationship between body size and walking speed. During videotaping in the field, air temperatures did vary between 22 and $30^{\circ} \mathrm{C}$ (mean $\pm \mathrm{SD}, 26.1$ \pm 2.3 ) and so may have had a significant effect on beetle performance. Nevertheless, the temperature term was not significant when included in the regression of body size effects in the field (walking speed $F_{1,64}=0.51, P>0.05$; area sweep rate $F_{1,64}=0.70, P>0.05$ ). Therefore, variation in temperature does not account for scatter in the field data (Fig. 5).

\section{Influence of Male Body Size on Fighting Ability}

Large-male advantage in aggressive competition for females in laboratory cages was indicated by the predominance of data points falling below the unity line in Fig. 6 (top). "Winning" males (either defending males that retained their mate after a contest or challenging males that separated a mated pair) averaged $7 \%$ larger in body length than losing males (mean \pm SE for winning 

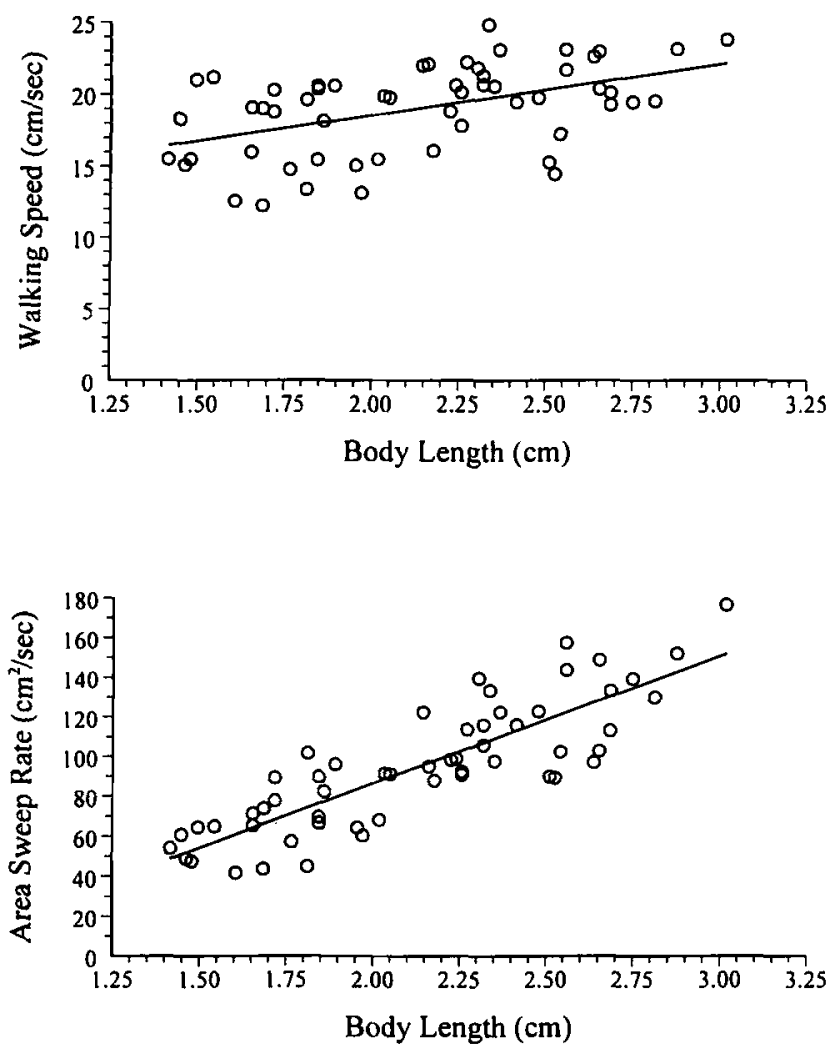

Fig. 4. Relationships between body length and walking speed (top) and antennal area sweep rate (bottom) for 55 male $P$. semipunctata in the laboratory. Best-fit regression equations were (top) $Y=3.54 X+11.4$ $\left(r^{2}=0.22, P=0.0002\right)$ and (bottom) $Y=64.3 X-42.2\left(r^{2}=0.71\right.$, $P<0.0001)$.

males, $2.48 \pm 0.04 \mathrm{~cm}$; losing males, $2.31 \pm 0.046 \mathrm{~cm}$; differences between means significant, paired-comparison $t$ test; $t_{1,44}=3.1, P=0.0033$ ). When males were of similar size $( \pm 10 \%$; points falling between the dashed lines in Fig. 6, top), the probability of winning was nearly equal, and the larger beetles lost $44 \%$ of 21 contests. However, when sizes of competing males differed more drastically (points falling outside the $10 \%$ zone), the larger individuals usually dominated, and $82 \%$ of winners were the larger beetle. Larger males also tended to win proportionally more conflicts than smaller males as shown by the preponderance of points falling below the unity line that represent $100 \%$ victory (one male of a pair winning five of five contests; Fig. 6, top).

In the field, large-male advantage was again indicated by the predominance 

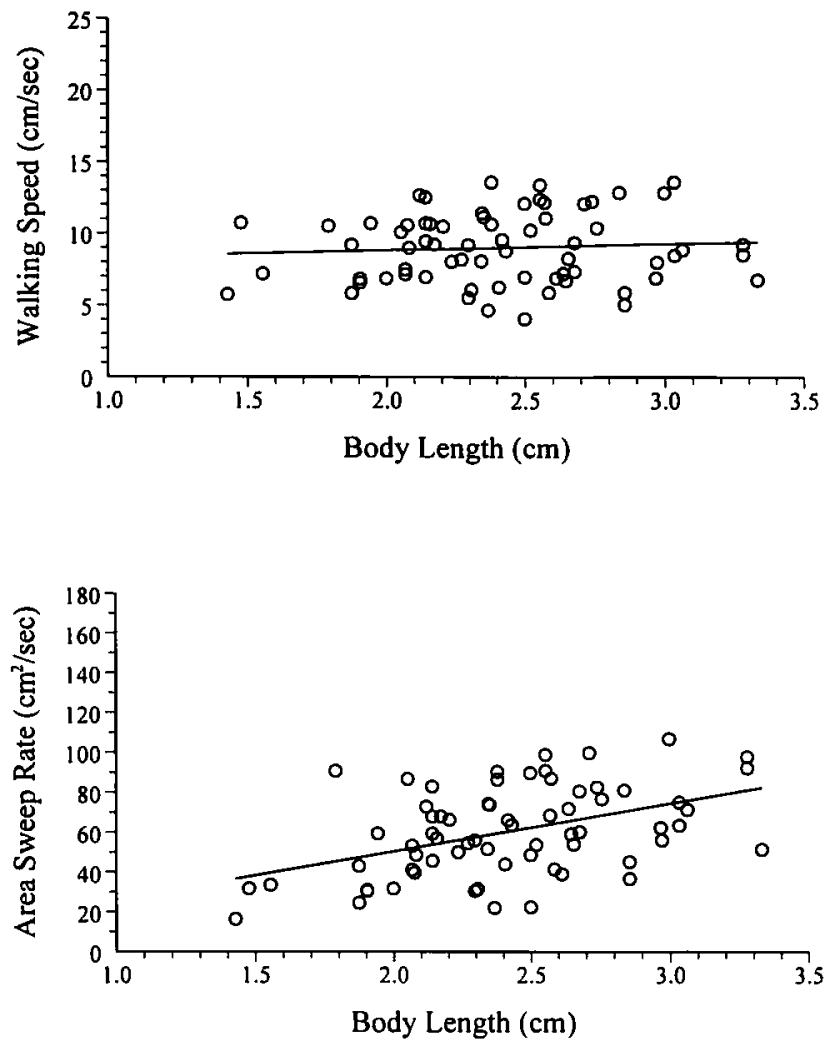

Fig. 5. Relationships between body length and walking speed (top) and antennal area sweep rate (bottom) for 67 male $P$. semipunctata on field logs. $X$ and $Y$ axes are scaled to match those of Fig. 4 for comparative purposes. Best-fit regression equations were (top) $Y=0.46 X$ $+7.9\left(r^{2}<0.01, P>0.05\right)$ and (bottom) $Y=24.2 X+2.2\left(r^{2}=\right.$ $0.21, P<0.0001$ ).

of data points falling below the unity line in Fig. 6 (bottom). Winning males averaged $14 \%$ larger than losing males (winners, $2.41 \pm 0.057 \mathrm{~cm}$; losers, 2.12 $\pm 0.056 \mathrm{~cm}$; differences between means significant, paired-comparison $t$ test; $\left.t_{1,33}=4.9, P=0.0001\right)$. As was the case in the laboratory, the outcome of conflicts between males was more unpredictable when males were similar in size as indicated by the points falling between the dashed $10 \%$ difference line in Fig. 6 (bottom). In five of nine cases, the losing male was slightly larger than the winner. However, the greatest number of points fell in the lower portion of the graph, showing that the larger male was nearly always the winner when males differed in size by greater than $10 \%$. 

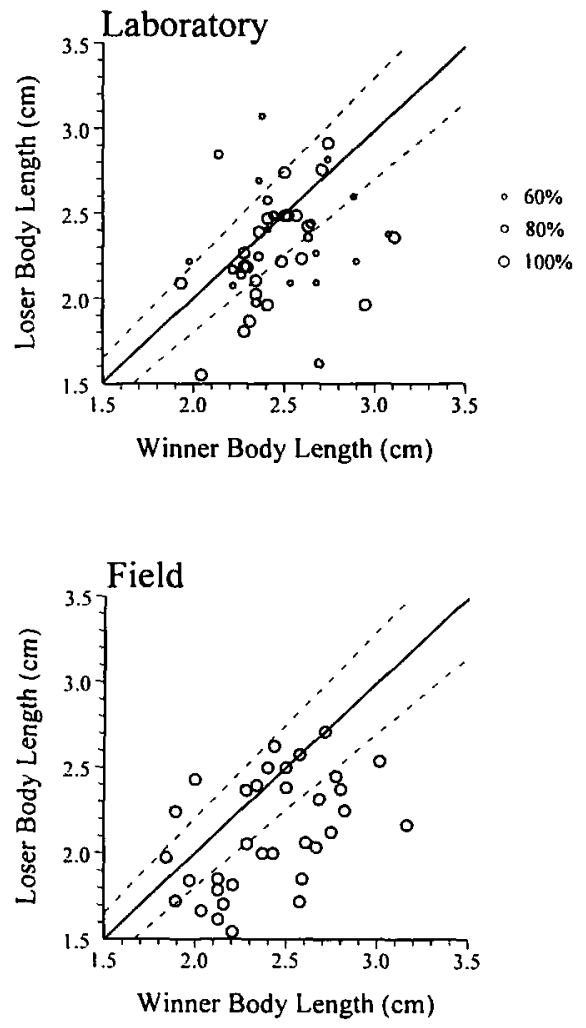

Fig. 6. Relationship between body lengths of "winning" and "losing" males in 45 laboratory cages containing a pair of males and a single female (top) and in 34 videotaped conflicts between males in the field (bottom). In the top graph, each point represents the proportion of five interactions in which the male improved his mating opportunities, the size of each data point representing the proportion of victories for the "overall winner" (see Materials and Methods). In the bottom graph, each point represents the outcome of a single fight and the "winner" was the male that improved his mating opportunities. The solid "unity" line (slope $=1$ ) indicates equal body size, and the area between dashed lines indicates $<10 \%$ difference in body size.

\section{DISCUSSION}

The largest adult female $P$. semipunctata that were captured on larval host trees tended to be paired with large males, and smaller females with smaller males. However, the great amount of scatter in these data (Fig. 1) suggests that associative pairing by size did not determine the mating structure of the population. The weak correlation between body sizes of mated females and males could have resulted from physical constraints in mating between beetles of very different body sizes, although no evidence of such constraints has been observed in the field (Hanks et al., 1996). Moreover, this correlation was unlikely to be due to mating preferences since neither sex appears to discriminate among potential mates (Hanks et al., 1996). Nonselective mating by males also explains why the mating success of females was independent of their size. In contrast, larger males had a greater probability of being paired with a female than smaller males.

Lawrence (1986) found that large-male dominance for the cerambycid Tetraopes tetraophthalmus (Forster), and size-independent mating success for 
the females, were the rule in populations having male-biased sex ratios. Similarly, the predominance of male $P$. semipunctata on our study trees and logs suggests that the mating structure of this population could be attributable to intense competition among males that reflects a relative scarcity of available mates. Males competed aggressively for females, but mating success also depended on the efficiency with which males located mates on the larval hosts.

In both laboratory and field studies, the antennal sweep rates of large male $P$. semipunctata were more than twice those of the smallest males. Because mate location depends primarily on antennal contact (Hanks et al., 1996), large size may confer a significant advantage in finding females, which contributes to the greater mating success of larger males. Large males may be able to search for females at a greater rate because their antennae are disproportionately longer, a result of the allometric relationship between body size and antennal length.

Our field data relating body size with male walking speeds or area sweep rates were considerably more scattered than the laboratory data (compare Figs. 5 and 4). Greater variance in the field data was apparently not a result of temperature variability, but was probably due to the irregularity of logs as a substrate for walking compared to the flat paper used in the laboratory study and, also, to the greater variation among beetles in age or diet. In addition, beetles in the laboratory study walked on the average twice as fast as those observed in the field. Differences in beetle behavior in laboratory and field probably reflect environmental conditions; beetles in the laboratory were undoubtedly stressed by handling under artificial light, while field beetles were undisturbed and in their natural environment. The laboratory data may therefore provide an indication of potential performance (how fast males can walk), while the field data provide a better assessment of typical performance (how fast males do walk). It is also significant that regression lines relating body size with walking and area sweep rates for the field data had smaller slopes in the field study (Fig. 5) than in the laboratory study (Fig. 4). This finding suggests that even though larger males are capable of walking faster than small males, they generally do not under natural conditions.

Large male $P$. semipunctata dominated smaller males in aggressive contests over females in both laboratory and field studies. Superior fighting abilities of larger males may also be related to antennae length since the antennae are used as weapons (Hanks et al., 1996). The reproductive advantage of larger male $P$. semipunctata may therefore reflect a competitive edge in defending mates and displacing rivals, as well as in locating mates on larval host trees.

\section{ACKNOWLEDGMENTS}

We are grateful to Robert Denno, Marc Linit, James Ott, John Pinto, Richard Redak, and George Roderick for their discussions and comments on the manuscript. We thank Kristin Kund and Ta Promlee for their technical 
assistance. We gratefully acknowledge financial support from the Rancho Santa Fe Association, the Elvenia Slosson Fund for Omamental Horticulture, the California Association of Nurserymen, the Califormia Departments of Food and Agriculture, Forestry and Fire Protection, and Transportation, and the University of Califomia IPM Project.

\section{REFERENCES}

Alcock, J. (1993). Animal Behavior: An Evolutionary Approach, Sinauer, Sunderland, MA.

Andersen, J., and Nilssen, A. C. (1983). Intrapopulation size variation of free-living and tree-boring Coleoptera. Can. Entomol. 115: 1453-1464.

Beeson, C. F. C., and Bhatia, B. M. (1939). On the biology of the Cerambycidae (Coleoptera). Indian For. Rec. Entomol. 5: 1-129.

Burley, N. (1983). The meaning of assortative mating. Ethol. Sociobiol. 4: 191-203.

Chemsak, J. A. (1963). Observations on the adult behavior of Xylotrechus nauticus (Mannerheim). Pan-Pacific Entomol. 39: 213-214.

Dusham, E. H. (1921). The painted hickory borer. Cornell Univ. Agr. Exp. Stat. Bull. 407.

Edwards, O. R., and Linit, M. J. (1991). Oviposition behavior of Monochamus carolinensis (Coleoptera: Cerambycidae) infested with the pinewood nematode. Ann. Entomol. Soc. Am. 84: 319-323.

Goldsmith, S, K. (1987). The mating system and alternative reproductive behaviors of Dendrobius mandibularis (Coleoptera: Cerambycidae). Behav. Ecol. Sociobiol. 20: 11-115.

Goldsmith, S. K. (1989). Feeding ecology and the mating system for Stenaspis verticalis arizonicus Casey (Coleoptera: Cerambycidae). J. Kans. Entomol. Soc. 62: 528-533.

Haack, R. A., and Slansky, F., Jr. (1987). Nutritional ecology of wood-feeding Coleoptera, Lepidoptera, and Hymenoptera. In Slansky, F., Jr., and Rodriguez, J. G. (eds.), Nutritional Ecology of Insects, Mites, Spiders, and Related Invertebrates, John Wiley, New York, pp. 449-487.

Hanks, L. M., McElfresh, J. S., Millar, J. G., and Paine, T. D. (1993). Phoracantha semipunctata (Coleoptera: Cerambycidae), a serious pest of Eucalyptus in Califormia: Biology and laboratoryrearing procedures. Ann. Entomol. Soc. Am. 86: 86-102.

Hanks, L. M., Millar, J. G., and Paine, T, D. (1996). Mating behavior of the eucalyptus longhomed borer (Coleoptera: Cerambycidae) and the adaptive significance of long "horns." J. Insect Behav. 9: 383-393.

Hughes, A. L., and Hughes, M. K. (1987). Asymmetric contests among sawyer beetles (Cerambycidae): Monochamus notatus and Monochamus scutellatus). Can. J. Zool. 65: 823-827.

Lawrence, W. S. (1986). Male choice and competition in Tetraopes tetraophthalmus: effects of local sex ratio. Behav. Ecol. Sociobiol. 18: 289-296.

McCauley, D. E. (1982). The behavioral components of sexual selection in the milkweed beetle Tetraopes tetraophthalmus. Anim. Behav. 30: 23-28.

Otte, D. (1979). Historical development of sexual selection theory. In Blum, M. S., and Blum, N. A. (eds.), Sexual Selection and Reproductive Competition in Insects. Academic Press, New York, pp. 1-18.

Paine, T. D., Miliar, J. G., and Hanks, L. M. (1995). Integrated program protects trees from eucalyptus longhomed borer. Cal. Agr. 49(1): 34-37.

Ridley. M. (1983). The Explanation of Organic Diversity, Oxford University Press, Oxford.

SAS Institute (1988). SAS/STAT. User's Guide for Personal Computers. Release 6.03, SAS Institute, Cary, NC.

Scriven, G. T., Reeves, E. L., and Luck, R. F. (1986). Beetle from Australia threatens Eucalyptus. Calif. Agr. 40(4): 4-6.

Sokal, R. R., and Rohlf, F. J. (1981). Biometry, Freeman Press, New York.

Thomhill, R., and Alcock, J. (1983). The Evolution of Insect Mating Systems, Harvard University Press, Cambridge, MA. 